\title{
Contrasting patterns of fig wasp communities along Mt. Wilhelm, Papua New Guinea.
}

by Souto-Vilarós, D., Houadria, M., Michalek, J., Sisol, M., Isua, B., Kuyaiva, T., Weiblen, G.D., Novotny, V. and Segar, S.T.

Copyright, publisher and additional information: this is the author accepted manuscript. The final published version (version of record) is available online via Wiley. This article may be used for non-commercial purposes in accordance with Wiley Terms and Conditions for Self-Archiving.

Please refer to any applicable terms of use of the publisher.

DOI: https://doi.org/10.1111/btp.12763 
LRH: Souto-Vilarós et al.

2 RRH: Fig wasps along an elevational gradient

5 Contrasting patterns of fig wasp communities along Mt. Wilhelm, Papua New Guinea.

6 Daniel Souto-Vilarós ${ }^{1,2,3}$ Mickal Houadria $^{1}$, Jan Michalek ${ }^{1}$, Mentap Sisol $^{4}$, Brus Isua ${ }^{4}$,

7 Thomas Kuyaiva ${ }^{4}$, George D. Weiblen ${ }^{5}$, Vojtech Novotny ${ }^{1,4}$, Simon T. Segar ${ }^{1,6}$

8

$9{ }^{1}$ Biology Centre of the Czech Academy of Sciences, Institute of Entomology, Branisovska

10 1645/31A, 370 05, South Bohemia, Czech Republic

$11{ }^{2}$ Faculty of Science, University of South Bohemia, Branisovska 1645/31A, 370 05, South

12 Bohemia, Czech Republic

$13{ }^{3}$ Department of Ecology, Faculty of Science, Charles University, Prague, Czech Republic

$14{ }^{4}$ New Guinea Binatang Research Centre, Nagada Harbour, Madang, Papua New Guinea

$15{ }^{5}$ Institute on the Environment, University of Minnesota, 1954 Buford Ave., Saint Paul, 16 Minnesota 55108, U.S.A.

$17{ }^{6}$ Department of Crop and Environment Sciences, Harper Adams University, New Port TF10 18 8NB, United Kingdom 
Abstract

The fig (Moraceae) and pollinating fig wasp (Agaonidae) mutualism is best known as a model system for the study of coevolution in plant-pollinator interactions and its central role in shaping vertebrate communities in tropical forests. Figs also host myriad antagonistic parasitic fig wasps which impose costs on both partners threatening mutualism stability. Spatio-temporal variation in parasitic wasp abundance is a key factor in mitigating these effects. Because fig wasps are temperature sensitive and likely vary in their ability to traverse environmental gradients, we expect community assemblages and abundance of both pollinating and non-pollinating fig wasps to respond to changes along an elevational gradient. In the present study, we compare the fig wasp communities and abundance of three fig species growing along the slopes of the Mount Wilhelm altitudinal gradient in Papua New Guinea. We quantified wasps from over 100 male fig trees and calculated seed set for 55 female trees along each of the species' distribution on the transect. Our results show that the abundance of both pollinating and non-pollinating fig wasps follow a mid-elevation peak, consistent with fig species richness found in the same transect. The patterns, however, are different according to the host's species distribution. Seed set remained relatively constant along the gradient for all species with some decrease along higher elevations, potentially affecting connectivity along the gradient. As suggested for insects in general, temperature and habitat diversity appear to play a fundamental role in the species richness and abundance of

39 fig wasps.

Key words: Ficus; pollination; non-pollinating fig wasps; seed set; altitudinal gradient. 

VARY WITH ELEVATION. These patterns, however, are different among different taxonomic groups (Warren et al. 1988, McCoy 1990, Peck et al. 2008, Maunsell et al. 2015). As insects are ectothermic, they are particularly sensitive to temperature (Arroyo et al. 1982, GarcíaRobledo et al. 2016) and correspondingly less diverse at higher elevations and lower latitudes. The vast majority of angiosperms are pollinated by insects which inextricably links plant and insect fitness (Lowry et al. 2008, Ollerton et al. 2011, Ellstrand 2014). The abundance of wasps and beetles tends to decrease with increasing elevation and instead, more abundant dipteran communities pollinate flowers at higher elevations, implying a shift in pollinator composition which influences plant reproductive strategies and success (Warren et al. 1988). Also affected by elevation is parasitoid wasp abundance and species richness. Both are highest at mid-elevations, due in part to the abundance of potential hosts. This distribution likely influences structure and function of food webs by affecting plant herbivore and/or pollinator interactions (Peck et al. 2008, Maunsell et al. 2015). Obligate pollination mutualisms offer a tractable and relatively simple model for measuring fitness related traits along environmental gradients (Souto-Vilarós et al. 2018) because species specificity is high and traits can be easily quantified. Parasites and parasitoids of mutualisms add an extra layer of complexity because direct and indirect costs on mutualistic partners can influence the stability of such mutualisms (Bronstein 2001), and in some cases, abiotic factors may even shift mutualists into parasites and vice versa (Kawakita et al. 2015). Studies focusing on the response of trophic interactions with increasing elevation have found that while there is a general trend for insect predation and parasitism rates to decline, the predators and parasitoids involved do not necessarily respond in the same manner and in many cases depend on host distribution, as well as their density 
and temporal overlap during key life stages (Péré et al. 2013, Maunsell et al. 2015, Corcos et al. 2018).

For this study, we focus on the fig (Moraceae) and fig-wasp (Agaonidae) mutualism, one of the most specialized nursery pollination systems (Cook \& Rasplus 2003), where the reproductive success of both parties depends on species-specific encounters. Briefly summarizing, female wasps emerge from the figs (called syconia) and are guided by volatile signals as they search for a receptive fig of the same host species. Upon landing, mated and pollen-loaded wasps enter the floral cavity through a narrow passage (ostiole) and pollinate the flowers within. While approximately half of described fig species are monecious, having both male and female flowers within the same fig, the remainder are functionally dioecious meaning that sexual function are segregated between trees (though they are anatomically gynodioecious; Bronstein 1988, Corlett et al. 1990). Monoecious figs contain both longstyled flowers (which frequently develop as seeds) and short-styled flowers that are more accessible for wasps to oviposit, thus housing the next generation of wasps. In dioecious species, male figs contain flowers suitable for oviposition and produce only wasps becoming nurseries while female fig trees deceive the wasps to enter and pollinate, but wasps are unable to oviposit in the long-styled flowers inside and so female fig trees produce only seeds (Galil \& Eisikowitch 1968, Kjellberg et al. 2005). Some fig-wasps are known for long distance pollen dispersal as these minute insects $(1-2 \mathrm{~mm})$ appear to be transported by wind over wide distances of up to $160 \mathrm{~km}$ (Ahmed et al. 2009, Kobmoo et al. 2010, Liu et al. 2015). Thus far, these findings have been restricted mostly to large monoecious trees which occur at naturally low densities. In contrast there is evidence that dioecious and under-canopy fig trees are clustered into dense local populations and so pollinating fig-wasps do not disperse over such long distances (Dev et al. 2011). Figs house a large number of non-pollinating fig wasps (NPFW) which parasitize pollinator larvae or compete for seed resources thus significantly 
90

91

92

affecting pollinator populations and consequentially, fig pollen dispersal (Kerdelhué \& Rasplus 1996, Weiblen et al. 2001, Weiblen 2002). NPFW have a fascinating ecology of their own: ranging from gallers which enter the syconia alongside pollinators to kleptoparasites which oviposit into pre-existing galls or parasitoids. Many parasitoids oviposit from the outside of the fig, the ovipositor length correlated with the fig developmental stage at which these wasps oviposit (Weiblen 2002, Cook \& Segar 2010, Borges 2015).

Some authors have suggested that the negative effect of parasitism is stabilized through temporal and spatial heterogeneity in non-pollinator occurrence and abundance, as well as variation in the availability of figs at the right developmental stage for them to invade.

So far, the distribution and abundance of NPFW along environmental gradients has not been well studied, despite the knowledge that parasitism varies with both phenotypic and environmental variation (Maunsell et al. 2015, Yu et al. 2018). We suggest that elevational gradients, which to some extent control for species pool effects, make excellent systems to study environmentally mediated variation in fitness traits and parasite loads. Such gradients provide natural spatial structure and environmental clines which mimic more wide scale variation across the range of a given resource species.

Specifically, we test the hypotheses that (1) pollinating wasp abundance decreases with elevation, (2) non-pollinator diversity and abundance have a mid-elevation peak due to mixing between lowland and highland communities, (3) seed set is highly dependent on pollinator abundance and so will follow the same trend as (1); finally, (4) because fig size limits the amount of seeds or developing wasps that can fit within them, we also test whether or not fig size (volume) varies along the gradient. 


\section{METHODS}

The study was conducted along an elevational gradient in the central range of New Guinea.

The continuously forested Mount Wilhelm $\left(5.7800^{\circ} \mathrm{S}, 145.0297^{\circ} \mathrm{E}\right)$ gradient ranges from lowland alluvial forest up to lower montane forest and has been previously described in detail elsewhere (Toussaint et al. 2014, Marki et al. 2016, Robillard et al. 2016). Our study was conducted at six sites each with approximately 500 meters elevational intervals from $200 \mathrm{~m}$ to 2,700m (all elevations stated as above sea level; table 1). Approximately half of the 150 Ficus (Moraceae) species recorded for the island occur there along the transect (Berg \& Corner 2005) and previous fig species surveys along the transect reveal that some of these species have wide elevational ranges (Novotny et al. 2005, Segar et al. 2017). For the present study, we focused on three dioecious species endemic to New Guinea and adjacent islands selected on the basis of their distribution along the transect: Ficus wassa Roxb., is a botanically recognized species abundant throughout the gradient with a wide distributional range occurring between $200 \mathrm{~m}$ and $2,700 \mathrm{~m}$ pollinated by the fig-wasp Kradibia wassae; Ficus arfakensis King, distributed between 200m and 700m and pollinated by Ceratosolen solitarius; Ficus trichocerasa Diels is represented by lowland and a highland subspecies with the nominate F.t. trichocerasa distributed between 700 and $1,200 \mathrm{~m}$ and the highland F.t. pleioclada distributed between 1,200 and $2,600 \mathrm{~m}$, these subspecies appear to be pollinated by undescribed species of Ceratosolen wasps. Recent genomic analyses have revealed that these species are pollinated by three, four and two species complexes, respectively (Souto-Vilarós et al. 2019), distributed in parapatry along the gradient. sites along the transect, we tagged several male and female trees of each locally available 
focal species and monitored them during the duration of the sampling. For each of the focal trees, we collected up to five ripe figs for each female tagged tree, stored them in plastic pots in a $70 \%$ ethanol solution and exported to the University of South Bohemia, Czech Republic for later dissection. Using a microscope, up to two figs selected haphazardly from each pot were dissected $(n=112)$ and all fully developed seeds and all available ovules were counted, seed set was calculated as the number of seeds divided by the number of ovules.

For each male tree, figs were sampled either through emergence or dissection methods (Segar et al. 2014). For the emergence method, we collected up to five D-stage figs (Galil \& Eisikowitch 1968), the stage when wasps are already hatched from the galls and are clustered within the fig cavity, and stored them in individual plastic pots covered with fine mesh. Wasps were allowed to emerge naturally from the figs $(n=113)$ and were immediately collected and stored in $100 \%$ ethanol. Wasp individuals were sorted to at least genus and morpho-species level. For the dissection method, a second set of D-stage figs were directly stored in $70 \%$ ethanol solution. All collections were sent to the University of South Bohemia for later dissection of figs and sorting and identification of wasps. Up to two figs per tree $(n=110)$ were selected haphazardly and dissected under a microscope and the total number of wasps recorded. Width and height were measured to the nearest $0.01 \mathrm{~mm}$ using Vernier callipers to calculate fig volume following the standard cone volume formula (as per Segar et al. 2017): $V=\pi r^{2} \frac{h}{3}$

To test the influence of elevation and fig species on fig volume, seed set and total number of wasps produced, we performed generalized linear models (GLMs) separately using collection site (as elevation) and fig species as explanatory variables. Minimal models were retained using standard backward selection by removing non-significant higher-level 

interactions. We used Welch Two Sample t-test to compare fig volume between male and 161 female figs, as there was no significant difference according to sex (see results), volume 162 analyses combined both sexes. Analyses on seed set and wasp numbers were conducted 163 separately for female and male figs. The full models run were: i) fig volume as a response to 164 elevation and species, ii) seed set as a response to elevation and species, iii) total wasps 165 number per fig as a response to elevation and species; further, we separated analyses on 166 wasps to include iv) number of pollinating wasps as a response to elevation and species and 167 v) number of non-pollinating wasps as a response to elevation and species. For all models we 168 fitted a quasipoisson error structure, except for seed set for which we used a Gaussian 169 distribution. Finally, multiple comparisons between elevations were tested for significance using Tukey's test of main effects as implemented in the General Linear Hypothesis function 171 glht in the R package 'multcomp' v.1.10 (Hothorn et al. 2008). All analyses were conducted 172 in $\mathrm{R}$ version 3.5.1 ( $\mathrm{R}$ Core team 2015). 


\section{RESULTS}

174

175

176

177

178

179

180

Fig Volume Variation Between Species And Elevation. - We measured volume for a total of 222 figs (female $n=112$, male $n=110$ ) for each species separately (details summarized in table 1). We initially tested fig volume separately according to tree sex but found no significant difference between them $(t=-1.048, \mathrm{df}=266.7, p=0.295)$ and so we analyzed the effect elevation has on fig volume for both sexes combined. Elevation affected fig volume, however, the strength and direction varied according to species (Fig. 1): there was a positive effect of altitude for $F$. arfakensis while fig volume remains almost constant for $F$. wassa with declines at the $1,700 \mathrm{~m}$ and the $2,700 \mathrm{~m}$ sites. In the case of $F$. trichocerasa, volume increased with elevation for both subspecies.

Seed Set Variation Between Fig Species And Elevation - The effect of fig volume and seed set were analyzed for female figs only using a total of 112 dissected figs and shows that in general, larger figs have higher seed set. Overall, seed production remains constant for all species along the transect (Fig. 2B) with the exception of a significant decrease of seed set for F. wassa at the $1,700 \mathrm{~m}$ site (Tukey HSD test shows significant difference between this site and all other $p .<0.04$ except at $200 \mathrm{~m})$. Important to note is that for this species, all mature female figs found at the highest elevation $(2,700 \mathrm{~m})$ were infested by maggots or decaying on the tree and so we were unable to calculate seed set.

\section{Wasp Abundance And Variation Between Fig Species Across Elevations - All} analyses pertaining to wasp numbers (both pollinators and parasites) were conducted on data from male figs only. Elevation played a significant role on the total number of wasps produced per fig with a distinct mid-elevation peak; however, the effect varies according to fig species (Fig 3). Wasp numbers steadily increased with elevation in $F$. arfakensis and $F$. wassa up to the $1,200 \mathrm{~m}$ site where the former appears to plateau at its range limit $(1,700 \mathrm{~m})$ 
and the latter sharply decreases beyond this point (Fig 3 ). In the case of $F$. trichocerasa, there is a significant decrease of total number of wasps per fig in subsp. trichocerasa while the total number of wasps for F. t. pleioclada remains constant between both elevations (Fig 3).

Separating the data into pollinator and non-pollinator numbers reveals a similar pattern. Pollinator numbers vary in response to elevation with a sharp increase at the midelevation peak (between $1,200 \mathrm{~m}$ and $1,700 \mathrm{~m}$ ) followed by a decrease in pollinator numbers in the highlands (Fig 4). In the case of NPFWs, the total number of wasps was affected by elevation but the effect varied among species (Fig 5). For both pollinating and nonpollinating wasps associated with $F$. arfakensis elevation had a positive effect on the total number of wasps, however in the case of NPFWs, there is a sharp decline at the species range limit $(1,700 \mathrm{~m})$ where very few NPFWs were found (mean $=0.75 \pm 0.49$; Table 1$)$, however, inter-sample variation was high. The effect of elevation for both pollinating and nonpollinating wasps from $F$. trichocerasa was similar for both subspecies. There was a general decline of wasp numbers in F. t. trichocerasa and no significant changes in wasp numbers from F. t. pleioclada. For F. wassa elevation played a significant role on the total number of pollinators per fig with an increase up to the $1,200 \mathrm{~m}$ site followed by a sharp decline increasing again at the highest elevation site. NPFW numbers remained relatively constant with significant differences between the $700 \mathrm{~m}$ and $1,200 \mathrm{~m}$ sites. Notably, the increase of parasitic wasp loads at the $700 \mathrm{~m}$ site is due to a considerable increase in non-pollinating wasp species richness, rather than exclusively numbers, as at this site we found most figs to host up to six different morphospecies of NPFW (Table 3).

In terms of community composition (Table 3), the most diverse community was found in the figs of $F$. wassa with up to eight different genera at the $700 \mathrm{~m}$ site. Overall, the diversity of NPFW of $F$. wassa remains between one and two genera at each site, with Philotrypesis and an Otitesellinae being the most abundant NPFWs found in these figs 
222 commonly found throughout $F$. wassa's range. In the case of $F$. arfakensis, we found two 223 very abundant species from the genus Apocrypta, and Sycophaga, in nearly all of the figs 224 sampled. The lowland populations $(200 \mathrm{~m}$ and $700 \mathrm{~m})$ supported up to three genera while in 225 the highest elevation of this species $(1,700 \mathrm{~m})$ we only found five individuals of Apocrypta. 226 The NPFW community of $F$. trichocerasa is similar in both subspecies with up to six 227 different genera with, individuals from Sycophaga being the most abundant in both 228 subspecies. Nevertheless, the genera between subspecies varied; for instance, in $F . t$. 229 trichocerasa we found one species of Apocrypta while in $F$ t. pleioclada we found wasps 230 from the subfamily Otitesellinae (possibly Micranisa) and Megastigmus, the latter only 231 known from figs in the section Malvanthera (Cook \& Segar 2010). 
The present study is, to our knowledge, the first to offer insight on fig seed set and wasp load variation along an elevational gradient. We found that elevation substantially affected the variables studied here (fig size, seed set and wasp production). However, the direction of the effect varies between species. As with other taxa (García-Robledo et al. 2016, Peters et al. 2016, Robillard et al. 2016), altitude plays an important role in abundance of both pollinating and NPFWs as well as species richness of the latter. Climatic changes that occur with increasing elevation have been shown to be some of the major factors affecting the distribution and survival of insect species (Jevanandam et al. 2013, García-Robledo et al. 2016). Temperature decreases with elevation while precipitation tends to increase at higher altitudes directly affecting insect development and survival while the same factors influence the surrounding vegetation, similarly affecting links along the trophic chain (i.e. herbivores and parasitoids). The results presented herein follow the Ficus-wide species trends presented by Segar et al. (2017) where fig species richness decreases with increasing elevation after a mid-elevation peak. We find wasp production follows this trend with a clear increase with elevation up to between $1,200 \mathrm{~m}$ and $1,700 \mathrm{~m}$ followed by a sharp decrease at higher elevations.

Fig female fitness, measured as seed set, remains relatively stable for all species (Fig 2) throughout the transect, similar to findings from Weiblen, Flick \& Spencer (1995) in $F$. variegata (69\% seed set), a dioecious species distributed through most of South East Asia; however, there is seed set variation between the different sites (Table 1). It is known that reduced seed set in figs is explained by the number wasps entering figs at receptivity (Corlett et al. 1990), but is also limited by the amount of pollen they carry, which is often related to 
emergence times (with early emerging wasps generally carrying more pollen than late emerging ones; Kjellberg et al. 2014). Our results show that even at the range limits of F.t. pleioclada $(2,200 \mathrm{~m})$, nearly every available ovule in female figs produced a seed suggesting little pollen limitation occurring when a fig is entered. There is evidence suggesting that seed set increases with foundress wasps entering receptive figs (Nefdt \& Compton 1996, Moore \& Greeff 2003), as well as more wasps entering bigger figs (Anstett et al. 1996). We did find variation in the size of figs along the gradient for some species. However, although the size of figs of $F$. arfakensis steadily increased with increasing elevation, seed set remained constant throughout the elevational range occupied by this species. We did not record the number of foundress wasps entering figs. It was hard to assess the occurrence of multiple foundress wasps in the dissected figs and so we were unable to relate seed set to the number of wasps entering receptive figs. Contrastingly, at the range limits of $F$. wassa $(2,700 \mathrm{~m})$, we were unable to find figs with seeds. It is known that fig trees abort figs if there are no available pollinators or if there is a mismatch between receptivity of figs and pollinator arrival (Suleman et al. 2011). The variation in seed set of $F$. wassa could be attributed to the lack of pollinators available at the highland sites (above $1,700 \mathrm{~m}$ ), where fig trees can survive the colder temperatures, but wasp survival may be limited (Chen et al. 2018).

We found variation in the total number of wasps in the studied species with increasing elevation having a significant effect (Fig 3). Studies on the monoecious $F$. petiolaris in northern Mexico concluded that foundress wasp distribution likely affects pollinator and nonpollinator abundances as well as overall seed production on the landscape (Duthie \& Nason 2016). Duthie \& Nason (2016) suggest that seed set and non-pollinator production are negatively affected by pollinator abundance which is in turn positively affected by the number of foundress wasps. Foundress arrival appears to be associated with tree aggregation suggesting that habitat connectivity plays an important role in the overall mutualism. Studies 
on $F$. racemosa along a disturbance gradient also found that production of non-pollinating fig wasps was higher in highly fragmented habitat (Wang et al. 2005). The Mount Wilhelm elevational gradient is continuously forested from the lowland up to the treeline. SoutoVilarós et al. (2019) found that these fig species do form highland and lowland populations often with a distinct mid-elevation 'contact-zone,' however, connectivity between these populations is high (Souto-Vilarós et al. 2019) suggesting that variation in wasp abundances may be related to varying conditions along the gradient instead of tree connectivity.

The ecology and life history strategies of these NPFWs is beyond the scope of this study, however, placing these wasps along the various trophic levels would greatly contribute to our as of yet limited understanding of NPFW communities. Species richness and abundance of galling wasps influences the diversity of parasitoids and hyperparasitoids.

Larger figs have greater number of flowers, which in turn offer more opportunities for wasp colonization (Borges 2015). Indeed, the largest figs in this study, F. arfakensis, supported the largest number of pollinating and non-pollinating fig wasps, but not the most diverse communities. Due to our limited taxonomic identification, we cannot rule out the ability of some of these NPFWs to use multiple host species. Although host specificity for NPFW may be less constrained than that of pollinators, it has been suggested that some degree of specificity is still frequent (Jousselin et al. 2008, McLeish et al. 2012, Duthie \& Nason 2016). Ecological and/or morphological requirements for NPFW development such as synchrony with fig development, volatile cues for host recognition, fig wall thickness and/or the presence of other wasps either as hosts, competitors or parasitoids may promote species specificity and/or invasion (Weiblen et al. 2001, Marussich \& Machado 2007, McLeish et al. 2012, Borges 2015, Farache et al. 2018). The co-occurrence of specific genera in different fig species at the same elevation may be of great interest from a community network perspective. Similarly, under-sampling individual trees may be a constraint in our results. It is known that 
307 NPFWs do not colonize all available figs within a patch due to asynchrony of developing fig.

308 Furthermore, the available species pool is likely to vary over time and space, and hence wasp

309 communities in a given fig crop depend on a multitude of factors (McLeish et al. 2012).

310 Molecular approaches would help greatly in determining species turnover and population

311 connectivity between the NPFW groups identified herein. Of particular interest are some of

312 the uncommon associations reported, particularly the occurrence of Otitesellinae wasps and

313 Megastigmus in F. t.pleioclada figs: both occur alongside Sycophaga in the same figs on the

314 same tree. One of the main challenges of describing NPFW assemblages is the variability in

315 their abundance and distribution across fig sections. Megastigmus species, for instance, are

316 only known from fig species in subsection Malvanthera (Cook \& Segar 2010), however, this

317 genus is known to be associated with a wide range of host plants both as seed feeders and

318 parasitoids of gall-makers (Auger-Rozenberg et al. 2006). Otitesellinae on the other hand, are

319 well known to parasitize sympatric figs from section Urostigma (Jousselin et al. 2006).

320 Within our sampling, we found at least two instances of Megastigmus and Otitesellinae wasps

321 within reared figs of $F$. t. pleioclada both coming from different elevations. Wider sampling

322 at both inter- and intraspecific level would help reveal if these associations were frequent or a

323 mistake on our part, or by the wasps themselves. Indeed unusual associations in communities

324 at the range edge of figs are more common. 
326 We thank villagers from all collecting sites for both providing local assistants and offering us

327 accommodation during our stay along the transect. We also would like to think all staff of the New

328 Guinea Binatang Research Centre in Papua New Guinea and the Papua New Guinea Forest Research

329 Institute and Department of Environment and Conservation for help granting export permits. We

330 would like to thank Alexandra Pruchova, Inga Freiberga, Katerina Puzejova, Klara Kopicova, Lucie

331 Houdkova, Michaela Uhrova, Pavlina Hajkova and Radka Jungova for their help dissecting figs. We

332 thank two anonymous reviewers, the handling and associate editors for constructive criticism for the improvement of this manuscript. We acknowledge funding from the Grant Agency of the Czech

334 Republic (grant number 15-24571S). STS acknowledges departmental support from Harper Adams 335 University.

\section{AUTHORS'CONTRIBUTIONS}

337 V.N., S.T.S., and D.S.V. planned the research and provided input at all stages. G.D.W. and B.I. suggested suitable species for the study. D.S.V., M.S. and T.K. conducted and managed all fieldwork aspects with initial assistance of S.T.S. J.M. assisted with data analysis and management of fig dissections. D.S.V. and M.H. analysed the data and interpreted the results. D.S.V. wrote the manuscript with substantial help from all authors. All authors contributed and approved the final version of the manuscript.

DATA ACCESSIBILITY

Data used for this study will be made available through public repositories such as Dryad upon acceptance of the manuscript. 
Ahmed, S., S. G. COMPton, R. K. ButLin, and P. M. GiLmartin. 2009. Wind-borne insects mediate directional pollen transfer between desert fig trees 160 kilometers apart. Proc. Natl. Acad. Sci. 106: 20342-20347.

Anstett, M. C., J. L. Bronstein, and M. HossAerT-MCKey. 1996. Resource allocation: a conflict in the fig/fig wasp mutualism? J. Evol. Biol. 9: 417-428.

Arroyo, M. T. K., R. Primack, and J. Armesto. 1982. Community Studies in Pollination Ecology in the High Temperate Andes of Central Chile. I. Pollination Mechanisms and Altitudinal Variation. Am. J. Bot. 69: 82-97.

Auger-Rozenberg, M. A., C. Kerdelhué, E. MagnouX, J. Turgeon, J. Y. Rasplus, and A. ROQUES. 2006. Molecular phylogeny and evolution of host-plant use in conifer seed chalcids in the genus Megastigmus (Hymenoptera: Torymidae). Syst. Entomol. 31: 47-64.

BerG, C. C., and E. J. H. CoRNER. 2005. Flora Malesiana, Series I. Volume 17 part 2. In Flora Malesiana Series I - Seed Plants vol. 17 Part 2. pp. 1-730.

Borges, R. M. 2015. How to be a fig wasp parasite on the fig-fig wasp mutualism. Curr. Opin. Insect Sci. 8: 34-40.

BRONSTEIN, J. L. 1988. Mutualism, antagonism, and the fig-pollinator interaction. Ecology 69: 12981302.

BRONSTEIN, J. L. 2001. The costs of mutualism. Am. Zool. 41: 825-839.

CHEN, H., Y. ZhANG, Y. PENG, and R. T. CORLETT. 2018. Latitudinal effects on phenology near the northern limit of figs in China. Sci. Rep. 4320.

COOK, J. M., and J. Y. RASPLUS. 2003. Mutualists with attitude: Coevolving fig wasps and figs. Trends Ecol. Evol. 18: 241-248.

CooK, J. M., and S. T. SEGAR. 2010. Speciation in fig wasps. Ecol. Entomol. 35: 54-66. 
Corcos, D., P. Cerretti, M. Mei, A. Vigna Taglianti, D. Paniccia, G. Santoiemma, A. De BIASE, and L. MARINI. 2018. Predator and parasitoid insects along elevational gradients: role of temperature and habitat diversity. Oecologia 188: 193-202.

Corlett, R. T., V. Boudville, and K. Seet. 1990. Seed and Wasp Production in Five Fig Species ( Ficus, Moraceae ). Malayan Nat. J. 44: 97-102.

Dev, S. A., F. KJellberg, M. Hossaert-MCKey, and R. M. Borges. 2011. Fine-Scale Population Genetic Structure of Two Dioecious Indian Keystone Species, Ficus hispida and Ficus exasperata (Moraceae). Biotropica 43: 309-316.

DUTHIE, A. B., and J. D. NASON. 2016. Plant connectivity underlies plant-pollinator-exploiter distributions in Ficus petiolaris and associated pollinating and non-pollinating fig wasps. Oikos 125.

ELLSTRAND, N. C. 2014. Is gene flow the most important evolutionary force in plants? Am. J. Bot. 101: 737-753.

Farache, F. H. A., C. B. Pereira, C. Koschnitzke, L. O. Barros, E. M. De C. Souza, D. T. Felício, F. Gatti, W. Cardona, J. Y. Rasplus, and R. A. S. Pereira. 2018. The unknown followers: Discovery of a new species of SycobiaWalker (Hymenoptera: Epichrysomallinae) associated with Ficus benjamina L. (Moraceae) in the Neotropical region. J. Hymenopt. Res. 102: $85-102$.

GALIL, J., and D. EISIKOWITCH. 1968. Flowering Cycles and Fruit Types of Ficus sycomorus in Israel. New Phytol. 67: 745-758.

García-Robledo, C., E. K. KuPrewicz, C. L. Staines, T. L. Erwin, and W. J. Kress. 2016. Limited tolerance by insects to high temperatures across tropical elevational gradients and the implications of global warming for extinction. Proc. Natl. Acad. Sci. 113: 680-685.

HothorN, T., F. BRETZ, and P. WESTFALL. 2008. Simultaneous inference in general parametric models. Biometrical J. 346-363. 
Jevanandam, N., A. G. R. Goh, and R. T. CORLETt. 2013. Climate warming and the potential extinction of fig wasps, the obligate pollinators of figs. Biol. Lett. 9: 20130041.

Jousselin, E., S. VAn NoOrt, V. Berry, J. Y. RAsplus, N. Rønsted, J. C. ERASMUS, and J. M. GREEFF. 2008. One fig to bind them all: Host conservatism in a fig wasp community unraveled by cospeciation analyses among pollinating and nonpollinating fig wasps. Evolution (N. Y). 62: $1777-1797$.

Jousselin, E., S. VAn NOORT, J. Y. RASPlus, and J. M. GREEFF. 2006. Patterns of diversification of Afrotropical Otiteselline fig wasps: Phylogenetic study reveals a double radiation across host figs and conservatism of host association. J. Evol. Biol. 19: 253-266.

KAWAKITA, A., K. MOCHIZUKI, and M. KATO. 2015. Reversal of mutualism in a leafflowerleafflower moth association: The possible driving role of a third-party partner. Biol. J. Linn. Soc. 116: $507-518$.

KerdelhuÉ, C., and J.-Y. RASPLus. 1996. Non-Pollinating Afrotropical Fig Wasps Affect the FigPollinator Mutualism in Ficus within the Subgenus Sycomorus. Oikos 3-14.

KJellberG, F., E. Jousselin, M. HossaerT-MCKeY, and J.-Y. RASPlus. 2005. Biology, ecology and evolution of fig pollinating wasps (Chalcidoidea: Agaonidae). Biol. Ecol. Evol. Gall Inducing Arthropods 539-572.

KJellberg, F., N. Suleman, S. Raja, A. TAyou, M. Hossaert-McKey, and S. G. COMPton. 2014. Some pollinators are more equal than others: Factors influencing pollen loads and seed set capacity of two actively and passively pollinating fig wasps. Acta Oecologica 73-79.

Kobmoo, N., M. Hossaert-McKey, J.-Y. RASPlus, and F. KJELLBerg. 2010. Ficus racemosa is pollinated by a single population of a single agaonid wasp species in continental South-East Asia. Mol. Ecol. 19: 2700-2712.

LiU, M., S. G. COMPTON, F. E. Peng, J. ZHANG, and X. Y. CHEN. 2015. Movements of genes between populations: Are pollinators more effective at transferring their own or plant genetic markers? 
LOWRY, D. B., J. L. ModliszewsKi, K. M. Wright, C. A. WU, and J. H. WiLlis. 2008. Review. The strength and genetic basis of reproductive isolating barriers in flowering plants. Philos. Trans. R. Soc. Lond. B. Biol. Sci. 363: 3009-3021.

Marki, P. Z., K. SAm, B. KoAne, J. Bolding KRISTEnsen, J. D. KenNedy, and K. A. JønsSOn. 2016. New and noteworthy bird records from the Mt. Wilhelm elevational gradient, Papua New Guinea Study area and Methods. Bull. B.O.C. 136: 263-271.

MARUSSICH, W. A., and C. A. MACHADO. 2007. Host-specificity and coevolution among pollinating and nonpollinating New World fig wasps. Mol. Ecol. 16: 1925-1946.

MAunsell, S. C., R. L. KitChing, C. J. BuRwell, and R. J. MorRis. 2015. Changes in hostparasitoid food web structure with elevation. J. Anim. Ecol. 84: 353-363.

MCCOY, E. D. 1990. The distribution of insect associations along elevational gradients. Oikos 58: $313-322$.

MCLeish, M. J., G. BeukMan, S. VAN NoORT, and T. C. Wossler. 2012. Host-plant species conservatism and ecology of a parasitoid fig wasp genus (chalcidoidea; sycoryctinae;arachonia). PLoS One 7: e44804.

MoORE, J. C., and J. M. GREEFF. 2003. Resource defence in female pollinating fig wasps: Two's a contest, three's a crowd. Anim. Behav. 66: 1101-1107.

NefdT, R. J. C., and S. G. Compton. 1996. Regulation of Seed and Pollinator Production in the FigFig Wasp Mutualism. J. Anim. Ecol. 65: 170-182.

Novotny, V., S. E. Miller, Y. Basset, L. CizeK, K. Darrow, B. Kaupa, J. Kua, and G. D. WEIBLEN. 2005. An altitudinal comparison of caterpillar (Lepidoptera) assemblages on Ficus trees in Papua New Guinea. J. Biogeogr. 32: 1303-1314.

OLLERTON, J., R. WinfREE, and S. TARRANT. 2011. How many flowering plants are pollinated by 
animals? Oikos 120: 321-326.

PeCK, R. W., P. C. BANKo, M. SchWARZFeld, M. EuAPARAdORN, and K. W. Brinck. 2008. Alien dominance of the parasitoid wasp community along an elevation gradient on Hawai'i Island. Biol. Invasions 10: 1441-1445.

PÉRÉ, C., H. JACTEL, and M. KENIS. 2013. Response of insect parasitism to elevation depends on host and parasitoid lifehistory strategies. Biol. Lett. 9: 20130028.

Peters, M. K. ET AL. 2016. Predictors of elevational biodiversity gradients change from single taxa to the multi-taxa community level. Nat. Commun. 7: 13736.

R CORE TEAM. 2015. R Core Team. R A Lang. Environ. Stat. Comput. R Found. Stat. Comput. Vienna, Austria. ISBN 3-900051-07-0, URL http//www.R-project.org/. 55: 275-286.

Robillard, T., F. Legendre, C. Villemant, and M. LePOnCE. 2016. Insects of Mount Wilhelm, Papua New Guinea T. Robillard, F. Legendre, C. Villemant, and L. Maurice (Eds.). Publications Scientifiques du Museum, Paris.

Segar, S. T., D. W. Dunn, C. T. DARwell, and J. M. CoOK. 2014. How to be a fig wasp down under: The diversity and structure of an Australian fig wasp community. Acta Oecologica 57: $17-27$.

Segar, S. T., M. Volf, J. Zima, B. Isua, M. Sisol, L. SAM, K. SAM, D. SOUto-Vilarós, and V. NOVOTNY. 2017. Speciation in a keystone plant genus is driven by elevation: a case study in New Guinean Ficus. J. Evol. Biol. 30: 512-523.

Souto-Vilarós, D., M. Proffit, B. Buatois, M. Rindos, M. Sisol, T. KuYaiva, B. Isua, J. MichaleK, C. T. Darwell, M. Hossaert-Mckey, G. D. Weiblen, V. Novotny, and S. T. SEGAR. 2018. Pollination along an elevational gradient mediated both by floral scent and pollinator compatibility in the fig and fig-wasp mutualism. J. Ecol. 106: 2256-2273.

Souto-Vilarós, D., A. Machac, J. MichaleK, C. T. Darwell, M. Sisol, T. Kuyaiva, B. Isua, G. D. Weiblen, V. NOVOtNY, and S. T. SEgAR. 2019. Faster speciation of fig-wasps than their 
SulEMAn, N., S. RAJA, Y. ZHANG, and S. G. COMPTON. 2011. Sexual differences in the attractiveness of figs to pollinators: Females stay attractive for longer. Ecol. Entomol. 36.

Toussaint, E. F. A., R. Hall, M. T. Monaghan, K. Sagata, S. Ibalim, H. V. Shaverdo, A. P. Vogler, J. Pons, and M. BALKe. 2014. The towering orogeny of New Guinea as a trigger for arthropod megadiversity. Nat. Commun. 5: 4001.

WANG, R. W., C. Y. YANG, G. F. ZHAO, and J. X. YANG. 2005. Fragmentation effects on diversity of wasp community and its impact on fig/fig wasp interaction in Ficus racemosa L. J. Integr. Plant Biol. 47: 20-26.

WARREN, S. D., K. T. HARPER, and G. M. BOOTH. 1988. Elevational Distribution of Insect Pollinators. Am. Midl. Nat. 120: 325-330.

WeIBLEN, G. D. 2002. How to be a Fig Wasp. Annu. Rev. Entomol. 47: 299-330.

WeIBLEN, G. D., and G. L. BuSH. 2002. Speciation in fig pollinators and parasites. Mol. Ecol. 11: $1573-1578$.

WEIBLEN, G. D., B. FLICK, and H. SPENCER. 1995. Seed set and wasp predation in dioecious Ficus variegata from an Australian wet tropical forest. Biotropica 27: 391-394.

WeIBLEN, G. D., D. W. YU, and S. A. WeSt. 2001. Pollination and parasitism in functionally dioecious figs. Proc. R. Soc. B Biol. Sci. 268: 651-659.

Wu, T., D. W. Dunn, H. Y. Hu, L. M. Niu, J. H. XiaO, X. L. PAN, G. FenG, Y. G. Fu, and D. W. HUANG. 2013. The occurrence of fig wasps in the fruits of female gynodioecious fig trees. Acta Oecologica 46: 33-38.

Yu, H., D. Liang, E. Tian, L. ZhENG, and F. KJellBerg. 2018. Plant geographic phenotypic variation drives diversification in its associated community of a phytophagous insect and its 
parasitoids. BMC Evol. Biol. 134.

494 
TABLE 1. Summary of collections per species including name of collection sites (female figs only)

\begin{tabular}{|c|c|c|c|c|c|}
\hline Ficus species & Collection Site & Elevation (m) & $\begin{array}{l}\text { Female figs (dissected) } \\
(\text { Total trees }=\mathbf{5 5})\end{array}$ & Fig volume $( \pm$ SE) & Seed set $( \pm$ SE $)$ \\
\hline \multirow{4}{*}{ F. arfakensis } & Kausi & 200 & 6 & $1.13 \pm 0.049$ & $0.739 \pm 0.058$ \\
\hline & Numba & 700 & 6 & $1.565 \pm 0.063$ & $0.758 \pm 0.028$ \\
\hline & Memeku & 1200 & 4 & $2.599 \pm 0.311$ & $0.91 \pm 0.031$ \\
\hline & Degenumbu & 1700 & 6 & $3.408 \pm 0.114$ & $0.794 \pm 0.039$ \\
\hline \multirow{2}{*}{ F. trichocerasa } & Numba & 700 & 9 & $0.781 \pm 0.051$ & $0.98 \pm 0.008$ \\
\hline & Memeku & 1200 & 10 & $1.5 \pm 0.219$ & $0.975 \pm 0.007$ \\
\hline \multirow{2}{*}{ F. pleioclada } & Degenumbu & 1700 & 9 & $0.479 \pm 0.017$ & $0.7 \pm 0.087$ \\
\hline & Snowpass & 2200 & 8 & $0.627 \pm 0.064$ & $0.796 \pm 0.092$ \\
\hline \multirow{6}{*}{ F. wassa } & Kausi & 200 & 12 & $0.599 \pm 0.059$ & $0.748 \pm 0.053$ \\
\hline & Numba & 700 & 12 & $0.569 \pm 0.03$ & $0.786 \pm 0.035$ \\
\hline & Memeku & 1200 & 10 & $0.653 \pm 0.054$ & $0.79 \pm 0.047$ \\
\hline & Degenumbu & 1700 & 12 & $0.464 \pm 0.037$ & $0.546 \pm 0.071$ \\
\hline & Snowpass & 2200 & 8 & $0.512 \pm 0.05$ & $0.795 \pm 0.112$ \\
\hline & Bruno Sawmill & 2700 & na & $0.351 \pm 0.026$ & na \\
\hline
\end{tabular}


TABLE 1 cont. Summary of collections per species including name of collection sites of collections (male figs only)

\begin{tabular}{|c|c|c|c|c|c|c|c|}
\hline Ficus species & Collection Site & Elevation (m) & $\begin{array}{l}\text { Male figs }^{b} \\
(\text { Trees }=103)\end{array}$ & $\begin{array}{l}\text { Infested figs } \\
(\%)\end{array}$ & $\begin{array}{l}\text { Number of } \\
\text { pollinators }( \pm \mathrm{SE})\end{array}$ & $\begin{array}{l}\text { Number of } \\
\operatorname{NPFW}( \pm \text { SE) }\end{array}$ & $\begin{array}{l}\text { Percentage } \\
\text { parasitism } \\
( \pm \text { SE })\end{array}$ \\
\hline \multirow{4}{*}{ F. arfakensis } & Kausi & 200 & $35(8)$ & 96 & $116.571 \pm 8.152$ & $22.677 \pm 3.489$ & $0.173 \pm 0.031$ \\
\hline & Numba & 700 & $9(7)$ & 88 & $247.222 \pm 34.29$ & $23.222 \pm 9.212$ & $0.098 \pm 0.037$ \\
\hline & Memeku & 1200 & $12(8)$ & 100 & $475.833 \pm 63.768$ & $98.833 \pm 16.692$ & $0.172 \pm 0.036$ \\
\hline & Degenumbu & 1700 & $9(7)$ & 25 & $526.556 \pm 82.802$ & $0.75 \pm 0.496$ & $0.002 \pm 0.001$ \\
\hline \multirow{2}{*}{ F. trichocerasa } & Numba & 700 & $8(8)$ & 100 & $136.875 \pm 23.394$ & $33.125 \pm 9.48$ & $0.225 \pm 0.074$ \\
\hline & Memeku & 1200 & $10(10)$ & 100 & $89 \pm 5.55$ & $14.889 \pm 2.939$ & $0.138 \pm 0.027$ \\
\hline \multirow{2}{*}{ F. pleioclada } & Degenumbu & 1700 & $27(13)$ & 95 & $65.296 \pm 8.552$ & $14.792 \pm 1.689$ & $0.245 \pm 0.018$ \\
\hline & Snowpass & 2200 & $12(11)$ & 91 & $64.667 \pm 18.915$ & $20.917 \pm 3.487$ & $0.377 \pm 0.074$ \\
\hline \multirow{5}{*}{ F. wassa } & Kausi & 200 & $15(6)$ & 75 & $126.2 \pm 20.018$ & $10.417 \pm 3.306$ & $0.082 \pm 0.03$ \\
\hline & Numba & 700 & $27(10)$ & 95 & $176.556 \pm 36.166$ & $29.792 \pm 5.08$ & $0.31 \pm 0.071$ \\
\hline & Memeku & 1200 & $15(4)$ & 73 & $344.467 \pm 42.177$ & $8.8 \pm 4.018$ & $0.037 \pm 0.022$ \\
\hline & Degenumbu & 1700 & $10(6)$ & 75 & $77.9 \pm 17.805$ & $7.625 \pm 2.656$ & $0.073 \pm 0.026$ \\
\hline & Snowpass & 2200 & $27(13)$ & 75 & $31.074 \pm 6.403$ & $17.826 \pm 3.258$ & $0.323 \pm 0.059$ \\
\hline
\end{tabular}


498 TABLE 2. Summary of generalized linear model results and Analysis of Variance for each model

499 tested. Values in bold indicate significant effect of the predictive term on the response variable.

\begin{tabular}{|c|c|c|c|c|}
\hline Response & Interaction & $\chi^{2}$ & $d f$ & $p$ \\
\hline \multicolumn{5}{|l|}{ Volume } \\
\hline & Elevation & 253.01 & 5 & $<0.001$ \\
\hline & species & 941.88 & 3 & $<0.001$ \\
\hline & species:Elevation & 104.90 & 5 & $<0.001$ \\
\hline \multicolumn{5}{|l|}{ Seed Set } \\
\hline & Elevation & 9.393 & 4 & 0.051 \\
\hline & species & 24.580 & 3 & $<0.001$ \\
\hline \multicolumn{5}{|c|}{ Total Wasps } \\
\hline & Elevation & 185.835 & 5 & $<0.001$ \\
\hline & species & 128.351 & 3 & $<0.001$ \\
\hline & Elevation: species & 66.865 & 5 & $<0.001$ \\
\hline \multicolumn{5}{|c|}{ Total Pollinators } \\
\hline & Elevation & 163.735 & 5 & $<0.001$ \\
\hline & species & 105.359 & 3 & $<0.001$ \\
\hline & Elevation: species & 59.101 & 5 & $<0.001$ \\
\hline \multicolumn{5}{|c|}{ Total NPFW } \\
\hline & Elevation & 66.61 & 5 & $<0.001$ \\
\hline & species & 41.273 & 3 & $<0.001$ \\
\hline & Elevation: species & 60.474 & 5 & $<0.001$ \\
\hline
\end{tabular}


TABLE 3. Summary of non-pollinating fig wasp community found at each elevation and Ficus species. Individuals were reared from individual

502 syconia and sorted to family and morphospecies when possible.

\begin{tabular}{|c|c|c|c|c|c|c|c|c|c|c|c|c|c|c|c|c|c|c|c|c|c|c|c|}
\hline Ficus species & $\begin{array}{l}\text { Collection } \\
\text { Site }\end{array}$ & $\begin{array}{l}\text { Elevation } \\
\text { (m asl) }\end{array}$ & 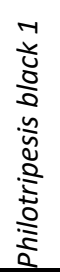 & 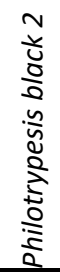 & 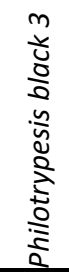 & 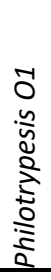 & 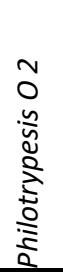 & 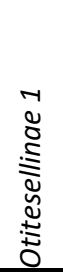 & 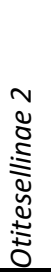 & 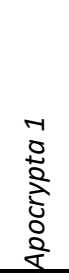 & 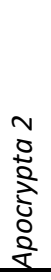 & 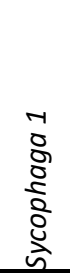 & $\begin{array}{l}1 \\
8 \\
8 \\
8 \\
\frac{1}{2} \\
8 \\
\vdots \\
5\end{array}$ & 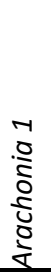 & 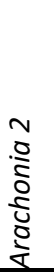 & 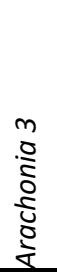 & 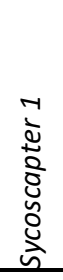 & 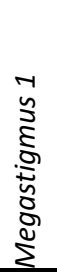 & 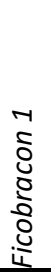 & 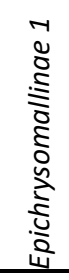 & 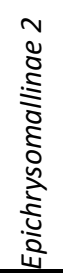 & 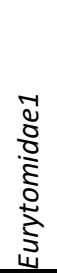 & 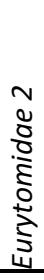 \\
\hline \multirow{4}{*}{ F. arfakensis } & Kausi & 200 & 1 & & & & & & & 62 & & 21 & & & & & & & & & & & \\
\hline & Numba & 700 & 19 & & & & & & & 86 & & 27 & & 2 & & & & & & & & & \\
\hline & Memeku & 1200 & & & & & & & & 534 & & 214 & & & & & & & & & & & \\
\hline & Degenumbu & 1700 & & & & & & & & 5 & & & & & & & & & & & & & \\
\hline \multirow{4}{*}{$\begin{array}{c}\text { F.t. } \\
\text { trichocerasa } \\
\text { F.t. pleioclada }\end{array}$} & Numba & 700 & & & & 3 & & & & & & & 171 & & & & 11 & & & & 2 & & \\
\hline & Memeku & 1200 & & & & & & & & & 2 & & 129 & & 2 & & & & & & & & \\
\hline & Degenumbu & 1700 & & & & & & & & & & & 109 & & & & & 10 & & & & & \\
\hline & Snowpass & 2200 & & 1 & & & & & 7 & & & & 182 & & 1 & & & 2 & & & 2 & & \\
\hline \multirow{6}{*}{ F. wassa } & Kausi & 200 & & & & & & 48 & & & & & & & & & & & & & & & \\
\hline & Numba & 700 & & & 6 & & 19 & 38 & & & & & & & & 34 & & & 3 & 34 & & 44 & 2 \\
\hline & Memeku & 1200 & & & 7 & & & & & & & & & & & & & & & & & & \\
\hline & Degenumbu & 1700 & & & 22 & & & 7 & & & & & & & & & & & & & & & \\
\hline & Snowpass & 2200 & & & 89 & & & 62 & & & & & & & & & & & & & & & \\
\hline & Sawmill & 2700 & & & 11 & & & & & & & & & & & & & & & & & & \\
\hline
\end{tabular}


FIGURE 1. Effect of elevation on fig volume for all (sub)species. Effect was calculated using generalized linear model with volume as the response variable to elevation and (sub)species interaction. The interaction of elevation and (sub)species identity is highly significant $\left(\chi^{2}=104.90, \mathrm{df}\right.$ $=5, p<0.001)$. Pairwise differences between elevations were tested using Tukey HSD post-hoc test. Different letters indicate significant differences between comparisons $(P<0.05)$.

FIGURE 2. Boxplots showing seed set per (sub)species and elevation. Effect was calculated using generalized linear model with seed set as the response variable to elevation and

511 (sub)species interaction. The interaction of elevation and (sub)species identity was not significant and so removed from the model through backwards elimination. The effect of elevation and (sub)species are significant (Elevation $\chi^{2}=9.393, \mathrm{df}=4, p<0.051$; (sub)species $\chi^{2}=24.580, \mathrm{df}=3, p<0.001$ ). Pairwise differences between elevations were tested using Tukey HSD post-hoc test. Different letters indicate significant difference between comparisons $(P<0.05)$.

517 FIGURE 3. Effect of elevation on total wasp production for all (sub)species. Effect was calculated using generalized linear model with total wasp as the response variable to elevation and (sub)species interaction. The interaction of elevation and (sub)species identity is highly significant $\left(\chi^{2}=66.865, \mathrm{df}=5, p<0.001\right)$. Pairwise differences between elevations were tested using Tukey HSD post-hoc test. Different letters indicate significant difference between comparisons $(P<0.05)$.

FIGURE 4. Effect of elevation on pollinating wasp production for all (sub)species. Effect was calculated using generalized linear model with total pollinating wasps as the response variable to elevation and (sub)species interaction. The interaction of elevation and (sub)species identity is highly significant $\left(\chi^{2}=59.101, \mathrm{df}=5, p<0.001\right)$. Pairwise differences between elevations were tested using Tukey HSD post-hoc test. Different letters indicate significant difference between comparisons $(P<0.05)$. 
529 FIGURE 5. Effect of elevation on parasitic wasp production for all (sub)species. Effect was 530 calculated using generalized linear model with total parasitic wasps as the response variable 531 to elevation and (sub)species interaction. The interaction of elevation and (sub)species

532 identity is highly significant $\left(\chi^{2}=60.474, \mathrm{df}=5, p<0.001\right)$. Pairwise differences between 533 elevations were tested using Tukey HSD post-hoc test. Different letters indicate significant 534 differences between comparisons $(P<0.05)$.

535 


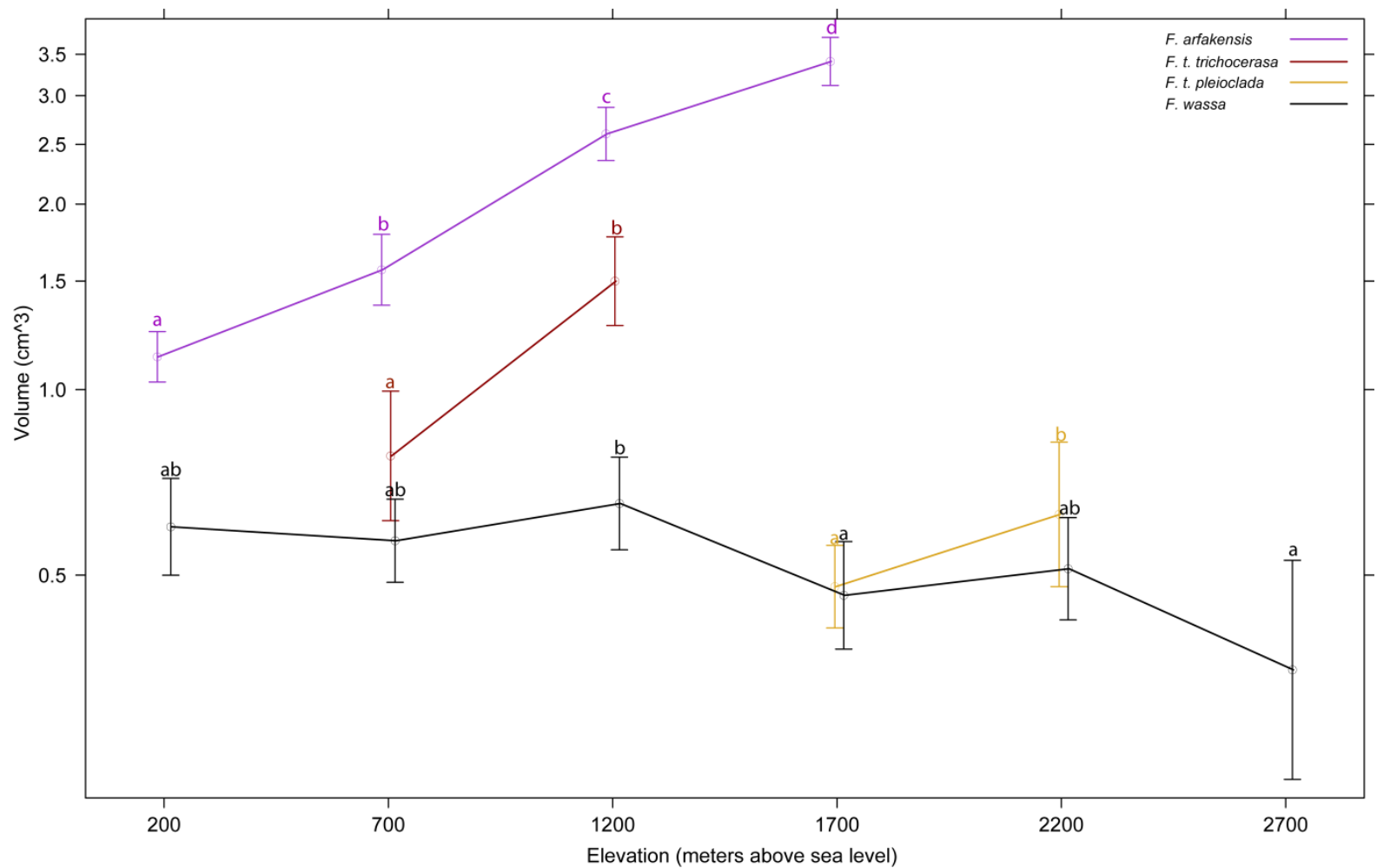

537

538 FIGURE 1

539

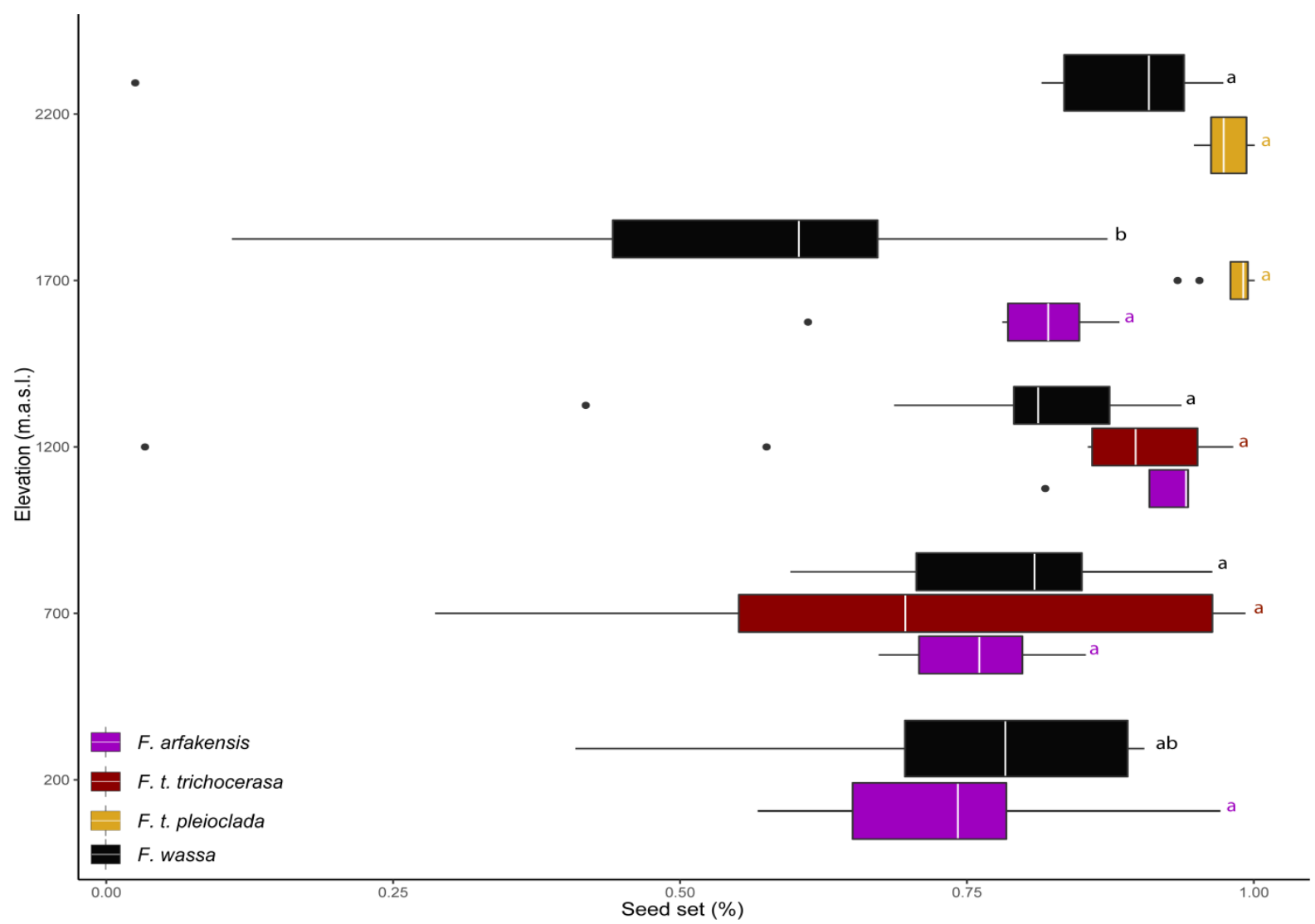

541 FIGURE 2 


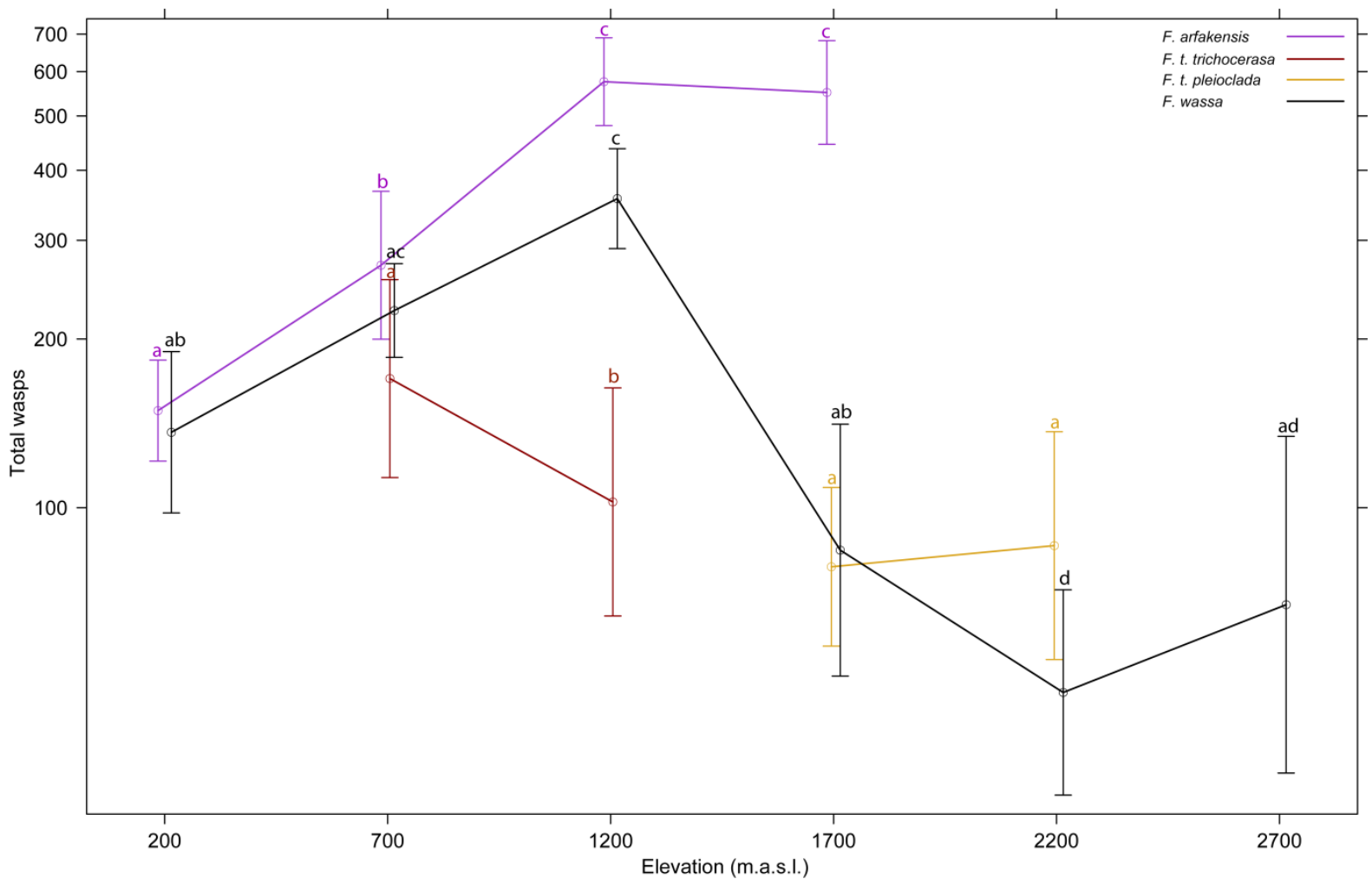

544 FIGURE 3

545

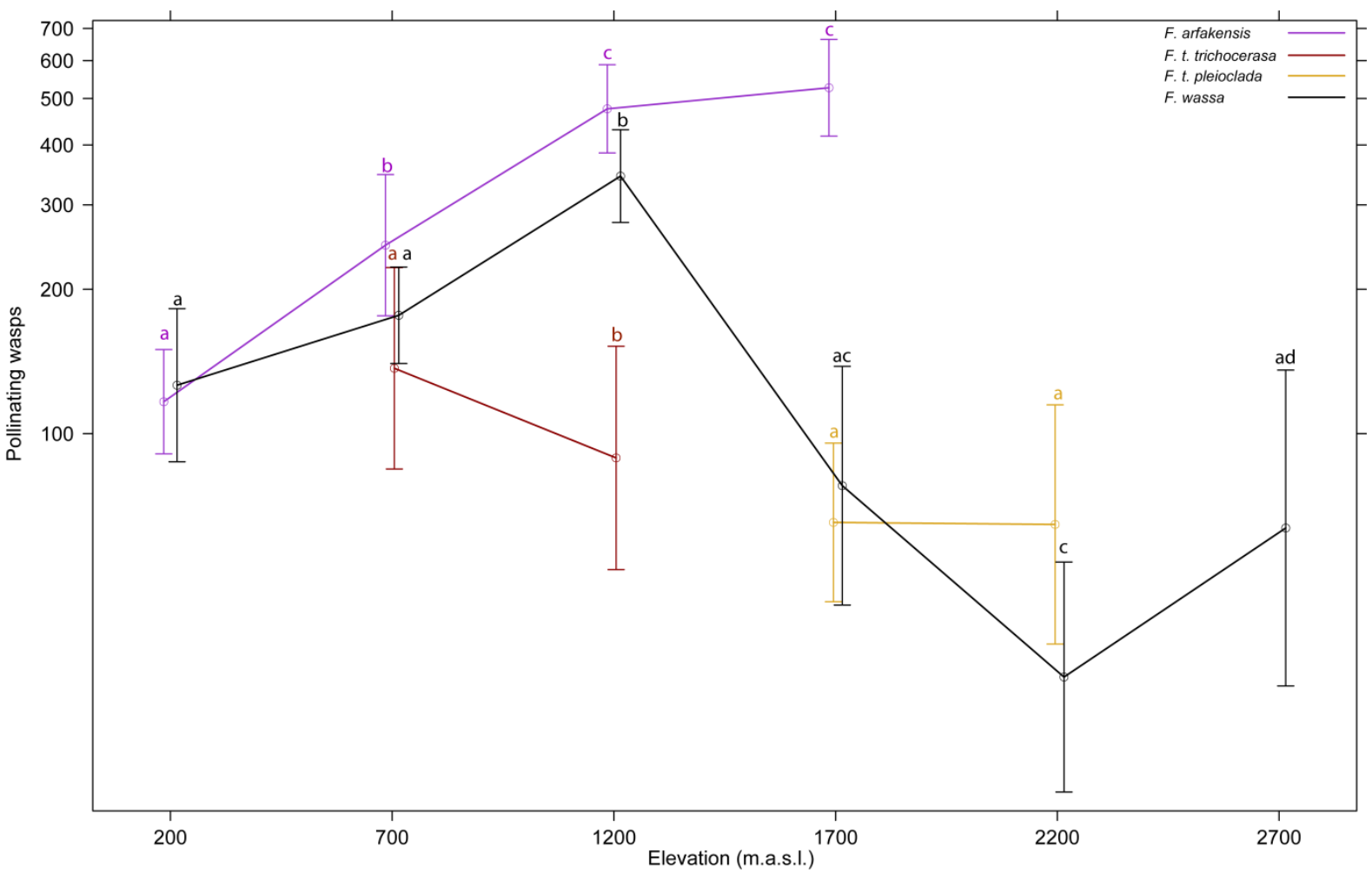

547 FIGURE 4 


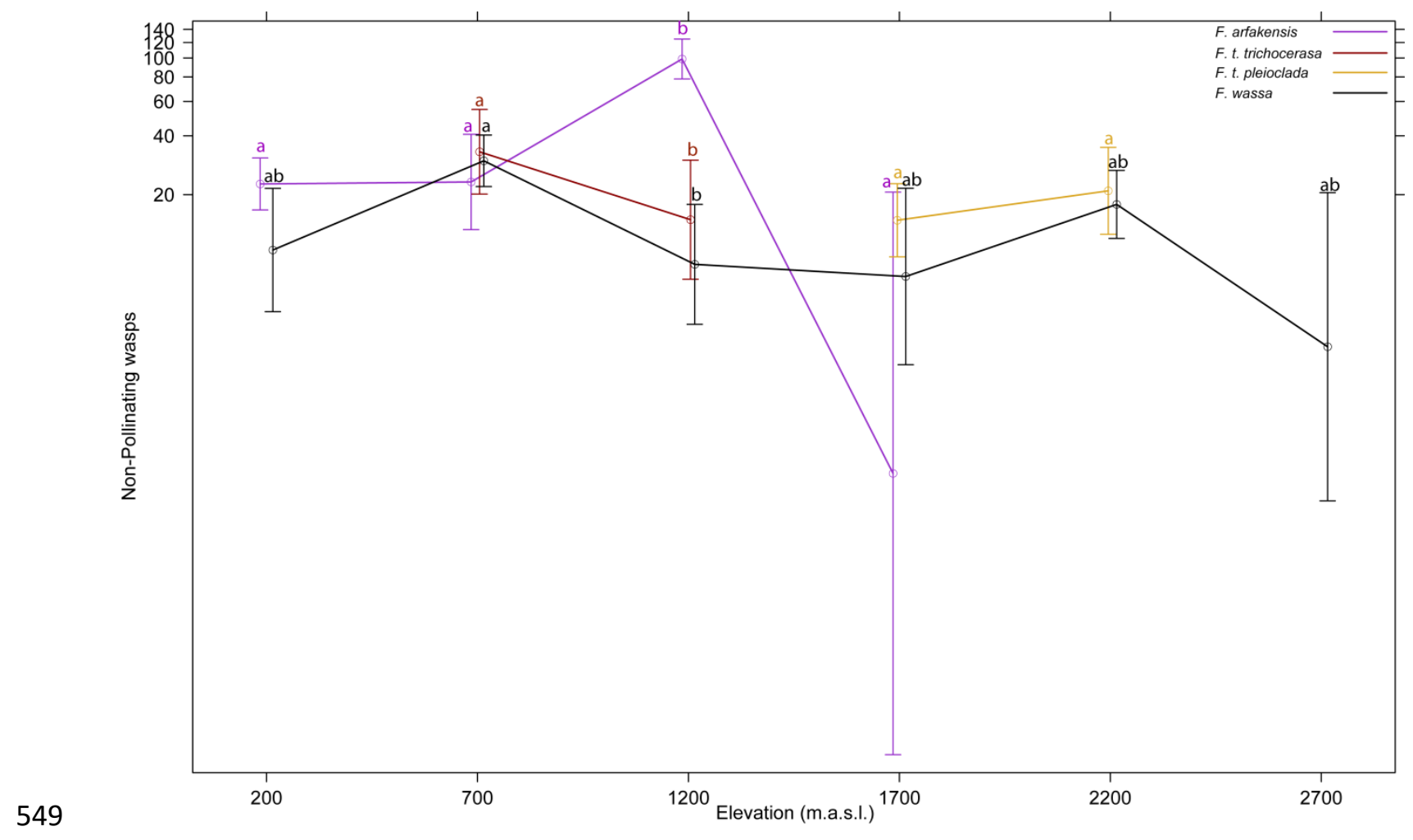

550 FIGURE 5 